\title{
Causas del control judicial a los actos administrativos disciplinarios proferidos por las procuradurías regionales de Tolima y de
}

\section{Cundinamarca ${ }^{1}$}

Causes of Judicial Control over the Disciplinary Administrative Acts Issued by the Regional Commissions of the Attorney General's Office in Tolima and Cundinamarca

Sergio Luis Mondragón Duarte ${ }^{2}$

Fecha de recepción: 15 de febrero de 2015

Fecha de aprobación: 27 de abril de 2015

\section{Resumen}

La Jurisdicción de lo Contencioso Administrativo puede ejercer control de legalidad sobre los actos administrativos sancionatorios expedidos por la Procuraduría General de la Nación, sus delegadas y demás agentes a través del medio de control de nulidad y restablecimiento del derecho. No obstante, dicho instrumento procesal no siempre se usa eficazmente porque existe un desconocimiento respecto de la forma de invocar correctamente las causales de nulidad que motivan su ejercicio judicial. Esa ausencia de discernimiento jurídico puede conllevar a que los disciplinados no logren una decisión judicial a su favor. Para contribuir a solucionar esa problemática, se realizaron una revisión bibliográfica y una investigación de

1 Artículo producto del proyecto de investigación titulado "Hallazgo y consolidación de líneas jurisprudenciales en derecho disciplinario", el cual generó un aporte a la Línea de Investigación en Derecho Disciplinario. Esta línea es liderada por el Semillero de Investigación en Derecho Disciplinario de la Universidad Cooperativa de Colombia, Sede Ibagué. El proyecto fue aprobado por el Comité Nacional para el Desarrollo de la Investigación (CONADI) en el año 2009. El citado proyecto de investigación ha sido financiado por la mencionada Universidad.

2 Abogado, especialista en Derecho Administrativo y Constitucional y en Contratación Estatal. Magíster en Derecho Público. Actualmente, docente de tiempo completo de la Universidad Cooperativa de Colombia, Sede Ibagué. Coordinador del Semillero de Investigación en Derecho Público de la Facultad de Derecho adscrita a la Universidad Cooperativa de Colombia, Sede Ibagué. Correo Electrónico: sergio.mondragon@campusucc.edu.co 
corte descriptivo e interpretativo. En este estudio, se analizaron las sanciones disciplinarias proferidas por las procuradurías regionales de Tolima y Cundinamarca cualitativa y cuantitativamente. En concreto, la investigación examinó las causales de la realización de un control judicial a actos disciplinarios emanados de esas dos procuradurías regionales. Los resultados de esas labores investigativas se dan a conocer en el presente artículo.

Palabras clave: control de legalidad, falta disciplinaria, nulidad disciplinaria, responsabilidad disciplinaria, sanción disciplinaria.

\section{Abstract}

The Jurisdicción de lo Contencioso Administrativo (Administrative Contentious Jurisdiction or Judicial Jurisdiction) can exercise control over punitive administrative actions issued by Attorney General's Office, its regional commissions or other agents through a means of control called annulment and right restoration. However, this procedural instrument is not always effectively used because there is a lack of knowledge regarding how to invoke properly causes for annulment of the act that motivates its judicial exercise. This lack of legal capacity may lead the disciplined to fail achieving a favorable court decision. To help solve this problem, a literature review and an investigation of the descriptive and interpretative were made. In this study, disciplinary sanctions issued by regional attorneys of Tolima and Cundinamarca were analyzed qualitatively and quantitatively. Specifically, this investigation examined the causes for conducting a judicial review of disciplinary actions emanated from these two regional attorney's offices. The results of these investigative efforts are presented in this article.

Keywords: Disciplinary annulment, disciplinary penalty, disciplinary responsibility, disciplinary sanction, legal control. 
Sergio Luis Mondragón Duarte

\section{INTRODUCCIÓN}

El ejercicio de la potestad disciplinaria y la aplicación del régimen disciplinario previsto para quienes ejercen funciones públicas han estructurado y desarrollado la noción de derecho disciplinario.

El derecho disciplinario puede ser aplicado por autoridades judiciales o autoridades administrativas o ejecutivas, caso en el cual siempre debe quedar abierta la posibilidad de una revisión judicial, sea sobre la decisión misma o sobre los efectos perjudiciales que haya producido o sobre la responsabilidad penal del funcionario que las haya proferido, nada se opone a que las actuaciones disciplinarias sobre la conducta de los funcionarios de la rama jurisdiccional del poder público, sean adelantadas ante esta, y que se les dé tratamiento jurisdiccional, sin la posibilidad de otras controversias judiciales ante la jurisdicción de lo contencioso administrativo (Isaza, 2009). Por ende, en todos aquellos casos en los cuales la sanción sea impuesta por la administración, por la Procuraduría General de la Nación o por un órgano de carácter diferente que no tenga como función básica el ejercicio de la potestad disciplinaria, la naturaleza de aquella, será administrativa, por tanto, se encontrará sujeta a control judicial; mientras que cuando sea impuesta por la Corte Suprema de Justicia o el Consejo de Estado, según sea el caso, al Procurador General de la Nación, por el Consejo Superior de la Judicatura, como administrador de justicia, será exclusivamente judicial (Isaza, 2009).

Por lo tanto, el derecho disciplinario es inherente a toda organización pública, independientemente de cual sea su naturaleza, y una parte integral de la administración de personal. Con el derecho disciplinario, se busca que el Estado, fiel a sus principios de organización política, configure y regule su funcionamiento en la sociedad. Esto se logra modelando la conducta de quienes están llamados directa o indirectamente a realizar sus fines.

Entonces, surge la Jurisdicción de lo Contencioso-administrativo en Colombia. Esta organización jurisdiccional puede ejercer control de legalidad a los actos administrativos disciplinarios expedidos los órganos de control disciplinario, especialmente, por la Procuraduría General de la Nación y de las procuradurías 
regionales contra servidores públicos. En este artículo, se reportan los resultados de una investigación sobre el control judicial a los actos administrativos disciplinarios proferidos por las procuradurías regionales de Tolima y de Cundinamarca a partir de la expedición de la Ley 734 de 2002.

\section{Marco teórico}

Este estudio se basó en la teoría de las nulidades en asocio con la teoría de la sanción disciplinaria. Según la primera teoría, la nulidad se define como "el estado de anormalidad del acto procesal, originado en la carencia de alguno de sus elementos constitutivos, o en vicios existentes sobre ellos, que potencialmente lo coloca en situación de ser declarado judicialmente inválido” (Maurino, 1995, p. 14).

Aplicando la teoría de las nulidades al derecho disciplinario, el estado de anomalía jurídico-legal del acto administrativo disciplinario se produce por la presencia de vicios en alguno de los elementos que forman parte de su creación. Dichos vicios no permiten que el acto produzca los efectos jurídicos que le dieron origen (invalidez del mismo) o, simplemente, que el acto no nazca a la vida jurídica (sea inexistente).

Por otra parte, la teoría de la sanción disciplinaria sostiene que la sanción disciplinaria debe presentarse siempre por actos o conductas oficiales, toda vez, que el poder disciplinario en un Estado de Derecho, se basa en dos pilares, un lado el poder ejercido por la jerarquía basado en órdenes o instrucciones del superior jerárquico, y de otro lado, el poder de control que se ejerce cuando no existe superior jerárquico, en ambos casos es claro que el poder disciplinario ejercido debe realizarse bajo el supuesto de conductas relacionadas con el cargo que el servidor público desempeńa (Isaza, 2009)

La teoría de la sanción disciplinaria junto con la teoría de las nulidades propenden por sostener que la nulidad es un estado anómalo de un acto procesal declarado por el funcionario competente (Reyes, 2003). En ese orden de ideas, la nulidad no es la causa ni tampoco la consecuencia de una infracción o sanción legal, respectivamente. Por el contrario, es un estado anormal de un acto. Este artículo aborda ese estado 
anómalo de los actos administrativos de índole disciplinaria. Entonces, el objetivo que pretendo alcanzar con este texto será desentrañar o dilucidar las causas que motivan la nulidad de los actos administrativos disciplinarios en los dos departamentos anteriormente mencionados.

\section{REVISIÓN DE LA LITERATURA JURÍDICA PERTINENTE}

\section{Sanciones a las que está sometido el servidor público}

Ahora bien, para comprender el control judicial a los actos administrativos disciplinarios proferidos por la Procuraduría General de la Nación y sus delegadas, debemos conocer primero los tipos de sanciones que éstas imponen. La clasificación de las sanciones disciplinarias están descritas taxativamente en el Artículo 63 la Ley 734 de 2002, más conocida como Código Disciplinario Único (CDU). Ellas conciernen la destitución e inhabilidad general, suspensión e inhabilidad especial, suspensión simple, multa o amonestación. A continuación, se describirá cada una en detalle.

La destitución e inhabilidad general opera para faltas graves de modalidad dolosa o culposa grave (Ley 734 de 2002, Art. 44). Según el Artículo 45 del CDU, esta sanción puede acarrear (a) la terminación de la relación laboral legal y reglamentaria que existe entre el servidor público con la administración, sin importar si el cargo del funcionario es de elección popular, libre nombramiento y remoción o de carrera administrativa, (b) la desvinculación del cargo, en los casos previstos en los artículos 110 y 278, numeral 1, de la Constitución Política o (c) la terminación del contrato de trabajo. En cualquier caso, esta sanción implica la imposibilidad de ejercer la función pública (inhabilidad pública) en cualquier cargo o función por el término señalado en el fallo (Ley 734 de 2002, Art. 45), el cual es superior a diez ańos, pero inferior a veinte años (Ley 734 de 2002, Art. 46). Solamente puede operar la inhabilidad permanente en el evento que la falta disciplinaria cometida por el servidor público afecte de forma directa el patrimonio económico de la administración. Además, la destitución siempre ocasiona la exclusión del escalafón o de la carrera (Ley 734 de 2002, Art. 45). 
La suspensión en el ejercicio del cargo e inhabilidad especial procede para las faltas graves dolosas o gravísimas culposas (Ley 734 de 2002, Art. 44). La suspensión consiste en separar al sancionado disciplinariamente del ejercicio de cargo público en el que se cometió la falta disciplinaria fallo (Ley 734 de 2002, Art. 45). Adicionalmente, la sanción accesoria de la suspensión es la inhabilidad especial, la cual significa la imposibilidad de ejercer la función pública en cualquier cargo distinto de aquel en el que se originó la falta (Ley 734 de 2002, Art. 45). Luego, el servidor público suspendido permanece en una situación que le deja incólume sus derechos laborales con relación a todos aquellos cargos o actividades que no quedan prohibidos ejercer por disposición del fallo. La inhabilidad especial tiene una duración de no menos de treinta días, pero no más de un año (Ley 734 de 2002, Art. 46). Tanto la suspensión en el ejercicio del cargo como la inhabilidad especial se aplicaran por el término señalado en el fallo (Ley 734 de 2002, Art. 45).

Según lo establecido por el Artículo 44 del CDU, la suspensión simple opera como consecuencia de la consumación de una falta disciplinaria en la modalidad culposa (se entiende como culpa grave). Este tipo de suspensión, al igual que la suspensión aplicable las conductas cometidas de forma grave, implica la separación temporal del cargo en virtud del cual se consumó la falta (Ley 734 de 2002, Art. 45). Al no consagrar la inhabilidad especial como sanción subsidiaria, no es óbice para ejercer cargos públicos distintos a los prohibidos desempeñar por orden expresa del fallo sancionatorio o para desempeñar el mismo cargo en el que se cometió la falta luego de haber cumplido el sancionado disciplinariamente con el tiempo de suspensión previsto en la providencia.

La multa aplica para la comisión de faltas leves de modalidad dolosa (Ley 734 de 2002, Art. 44). La multa es una sanción de tipo patrimonial dirigida a causar un impacto en el peculio del sancionado disciplinariamente (Ley 734 de 2002, Art. 45; Isaza, 2009). La multa debe guardar una debida proporcionalidad entre la gravedad de la falta y la sanción impuesta; así, se salvaguarda el principio de igualdad (Corte Constitucional, 1996). La multa no está encauzada a resarcir o indemnizar a la administración por el acto antijurídico cometido, sino con el fin de sancionar al funcionario de forma correctiva por la falta cometida en el ejercicio del cargo (Isaza, 
2009). Así, se espera que el sancionado cambie su comportamiento para adaptarse al mejoramiento en la prestación del servicio público.

Finalmente, la amonestación surge como sanción para las faltas leves cometidas en la modalidad culposa (Ley 734 de 2002, Art. 44). La amonestación consiste en un llamado de atención que realiza el superior o jefe de la entidad pública al disciplinado de manera escrita (Ley 734 de 2002, Art. 46). La amonestación debe registrarse en la hoja de vida del último (Ley 734 de 2002, Art. 46). El motivo real de la imposición de este tipo de sanción es hacer un reproche moral a quien va dirigida. Con esta represión escrita, no sólo se pretende subsanar la falta cometida, sino inspirar amor en el servidor público hacia sí mismo y hacia la administración. Así, se aspira a adecuar su comportamiento a la necesidad de garantizar una prestación apropiada del servicio estatal.

\section{Pretensiones disciplinarias}

El servidor público sancionado puede invocar pretensiones para invalidar la decisión de origen disciplinario, la cual es tomada por el funcionario adscrito a la entidad disciplinable. El sancionado puede entablar una demanda de nulidad y restablecimiento del derecho dirigida a declarar la invalidez de un acto administrativo disciplinario.

La Acción de Nulidad y Restablecimiento del Derecho se dirige no sólo a obtener la nulidad del acto administrativo, con el cual busca el restablecimiento de la legalidad para asegurar la actuación licita de la administración, sino además, que se restablezca el derecho que se ha vulnerado, le indemnicen los dańos, o le restituyan lo indebidamente pagado. Mira ante todo el interés particular de quien la ejerce. Sin embargo, existen eventos en los cuales con la acción de simple nulidad se obtienen efectos resarcitorios, en aquellos eventos en que la nulidad del acto produce el restablecimiento automático del derecho para quien haya ejercido la acción dentro del término de caducidad que la ley seńala para quien podría haber sido el titular de la Acción de Nulidad y Restablecimiento. Esta característica de la Acción de Nulidad y Restablecimiento del Derecho, 
obliga a que, al momento de elaborar la pretensión, deba solicitare no solo la nulidad del acto administrativo que ha sido expedido con violación de normas superiores, sino que, además, debe incluirse la condena consecuencial, pues el carácter rogado de la jurisdicción coloca al juez en la posición de condenar únicamente en la sentencia, en la forma como se le solicite el restablecimiento del derecho. (Palacio, 2010, p. 277)

No obstante, la expedición del fallo judicial a favor o en contra del servidor público es de carácter relativo. Ese carácter se debe a que, para la emisión del mismo, el juzgador prevé o tiene en cuenta aspectos sustanciales de carácter punitivo o procesal, tales como la graduación de la sanción impuesta al servidor público, la gravedad o levedad de la falta cometida por el mismo, el acervo probatorio que da cuenta de la certeza de la comisión o no consumación de la conducta por parte del servidor público, al igual que la veracidad del contenido de los aspectos fácticos, pretensiones, normas violadas, concepto de la violación que transcribe en el libelo de demanda el accionante.

\section{Causales de nulidad}

El Artículo 143 de la Ley 734 de 2002, del Código Disciplinario Único (CDU), establece las siguientes causales de nulidad en materia de derecho disciplinario: "la falta de competencia del funcionario para proferir el fallo; la violación del derecho de defensa del investigado y la existencia de irregularidades sustanciales que afecten el debido proceso" (Procuraduría General de la Nación, 2004, p. 65).

Respecto de la primera causal de nulidad, deben hacerse varias aclaraciones. La falta de competencia para proferir un fallo consiste en el adelanto de un proceso disciplinario por parte de un funcionario que carece de competencia para ello. En virtud de lo expuesto por el Artículo 75 del CDU, son funcionarios competentes para emitir providencias de índole disciplinario: la Procuraduría General de la Nación, la Superintendencia de Notariado y Registro, el Consejo Superior o Seccional de la Judicatura, las Personerías, las Oficinas de Control Interno Disciplinario de todas las entidades públicas y demás órganos del Estado de las administraciones central 
y descentralizado territorialmente y por servicios, incluido la Fiscalía General de la Nación.

La función disciplinaria de la Procuraduría es una. Entonces, pese a que el legislador distribuye la actuación disciplinaria entre distintos funcionarios de la Procuraduría, cuando las actuaciones son surtidas por el funcionario al que le incumbía fallar, no se puede decretar la nulidad.

La incompetencia del funcionario radica en la ausencia o desconocimiento del grado de jurisdicción que le corresponde a un juez para tratar un asunto. La jurisdicción depende de los factores de competencia que legalmente existen, por ejemplo: (a) el factor subjetivo, correspondiente a la calidad del sujeto disciplinario, al tenor de lo expuesto por el Art. 75 de la Ley 734 de 2002; (b) el factor objetivo, el cual atañe a la naturaleza del hecho, de conformidad con el contenido dispuesto en el Decreto 262 de 2000; (c) el factor territorial, el cual concierne al lugar donde se consumó la falta disciplinaria, en virtud de lo referido por el Art. 80 de la Ley 734 de 2002; (d) el factor funcional, relacionado con el servicio, rango o función prestada por el servidor público; y, finalmente, (e) el factor de conexidad, comprendido en los Arts. 81 y 151 de la Ley 734 de 2002.

En lo que concierne a la violación del derecho de defensa y/o audiencia del investigado, se puede acotar que las violaciones de este tipo se pueden presentar por acción u omisión que detengan o impidan el ejercicio de una defensa seria, oportuna, real o material y técnica. Los derechos de defensa se deben ejercer de manera pronta, cumpliendo con los términos y con las formalidades prescritas en el Código Disciplinario Único. De lo contrario, se estaría incurriendo en una causal de nulidad, debido a que el derecho no puede ser objeto de discrecionalidad o abuso.

Además, cabe destacar que se requiere de la materialización o de la clara o efectiva transgresión del derecho del acusado para actuar dentro del proceso (Navas, 2004). Ejemplo de esa transgresión sería no permitir al acusado ser escuchado en versión libre, no recibirle sus descargos, practicarle pruebas que no pueda controvertir luego o, simplemente, dejar de practicar las pruebas que al acusado solicita, sin atender a criterios jurídicos como los de pertinencia, conducencia y utilidad probatoria. 
Finalmente, para que proceda la tercera causal de declaración de nulidad en contra de un acto disciplinario, se requiere que una actuación afecte de forma sustancial o real al derecho fundamental al debido proceso. Por ejemplo, se declararía la nulidad si no se diera cumplimiento al trámite o a los requisitos esenciales que dieron origen al acto. Adicionalmente, "la prueba obtenida con violación al debido proceso es nula de plano, a menos que sea el único mecanismo probatorio fehaciente, idóneo y determinante para demostrar los hechos y las pretensiones objeto del proceso" (Navas, 2004, pp. 439-440). Para ahondar en el derecho al debido proceso en un proceso disciplinario, remítase a Corte Constitucional (1994).

Igualmente, es pertinente mencionar que el juez de primera instancia y el juez de segunda instancia deben estimar, valorar y ponderar las causas que originaron la presunta anomalía para determinar si realmente la irregularidad fue tan trascendental que irrumpió en el debido proceso del investigado o acusado disciplinariamente. Solo así puede existir una irregularidad de carácter esencial dentro del proceso disciplinario que lo invalide por quebrantar el debido proceso.

\section{Control judicial a los actos administrativos disciplinarios}

En enero de 2011, el Congreso de Colombia expidió el Código de Procedimiento Administrativo y de lo Contencioso Administrativo (CPACA), mediante la Ley 1437 de 2011. Según lo consagrado por el Artículo 138 de dicha ley, la Jurisdicción de lo Contencioso administrativo puede ejercer control de legalidad a los actos administrativos disciplinarios proferidos por la Procuraduría General de la Nación (Consejo de Estado, Sentencia 2982 de 2004), sus delegadas y demás agentes con base en las causales de nulidad que plantea el Artículo 137 de la misma normatividad.

El control de legalidad que ejerce la Jurisdicción de lo Contencioso Administrativo corresponde simplemente a un proceso de revisión judicial que adelantan los juzgados administrativos, tribunales administrativos y el Consejo de Estado (Consejo de Estado, 2011b). Este proceso tiene como objetivo verificar que dentro del proceso disciplinario adelantado contra un servidor público por la presunta comisión de una falta de orden disciplinario, no se hayan infringido las garantías constitucionales 
y legales que han sido otorgadas por el legislador a los investigados, acusados y sancionados disciplinariamente dentro del trámite procesal que se lleve a cabo para imponerles o eximirlos de sanciones (Consejo de Estado, 2004; 2005).

El control de legalidad a actos administrativos disciplinarios no constituye una tercera instancia sino que se establece para verificar si el proceso disciplinario en la instancia administrativa se adelantó con el respeto a los derechos del debido proceso y derecho a la defensa, y en general si la decisión se ajustó a derecho. Sin más valoraciones que las estrictamente formales, su papel se contrae a verificar si la actuación disciplinaria se ajustó de manera razonable a las reglas de la hermenéutica jurídica y la aplicación e interpretación de la ley disciplinaria.

De hecho, el control jurisdiccional de legalidad del proceso disciplinario no puede convertirse en una tercera instancia porque el Juez Administrativo no puede fungir como un operador de la norma disciplinaria. En ese sentido, su función de estudio de legalidad a este tipo de actos se limita netamente a validar si la actuación disciplinaria se ajustó de manera razonable a las reglas de la hermenéutica jurídica y a la aplicación e interpretación de la ley disciplinaria. Sin embargo, no puede entrar a propiciar debate o conflicto jurídico entre las partes con el fin de llegar a controvertir el contenido de los cargos formulados al sancionado disciplinariamente.

Una disparidad de criterios de interpretación entre el juez de la función disciplinaria y el juez contencioso-administrativo que derive en una actuación ilegitima autoriza el control contencioso administrativo (Gómez, 2009). Dicho control debe ser morigerado y estrictamente ceńido a la legitimidad del acto, acorde a lo dispuesto en el estatuto constitucional y legal (Gómez, 2009). El mismo acto puede obligar a la exclusión de corrección del acto administrativo sancionador, la valoración probatoria y el planteamiento de nulidades, sin atender necesariamente a los principios que gobiernan su declaratoria (Art. 143 parágrafo de la Ley 734 de 2002 y 310 de la Ley 600 de 2000). Casos excepcionales ocurren cuando, de manera injustificada, las reglas de la sana crítica, la lógica y el sentido común son quebrantadas en el ámbito que las rodea. Sin embargo, no se trata de reparar o modificar dicha oportunidad contencioso-administrativa en la práctica de pruebas. Para efectos probatorios, debe 
utilizarse el mecanismo de la revocatoria directa, con el cual se abre la posibilidad de emplear extensivamente las reglas del control contencioso administrativo.

Concretamente, el control de legalidad puede ejecutarse por medio de la acción de nulidady restablecimiento delderecho, como se mencionó anteriormente. LaJurisdicción de lo Contencioso Administrativo puede decretar la nulidad y restablecimiento del derecho de actos administrativos de orden disciplinario emanados de la Procuraduría General de la Nación.

La jurisdicción contenciosa administrativa sólo está autorizada para declarar la nulidad de un acto administrativo de carácter disciplinario, so pena de incurrir en abuso de autoridad y consecuentemente de inmiscuirse en funciones autónomas de otros administradores de justicia, en sentido material, cuando se presente una violación al debido proceso, lo cual ocurre cuando en forma manifiesta se observe que el funcionario competente para adelantar el correspondiente proceso actuó de una manera abiertamente irrazonable, o desproporcionada, con abuso de sus funciones (Gómez, 2009).

Dicho control sólo puede hacerse efectivo si se ahonda en el estudio de vicios que sobre los mismos puedan acarrear su declaratoria de nulidad e incluso su inexistencia. Por consiguiente, la presente investigación se dirigió a estudiar las causales de la realización de un control judicial a actos disciplinarios proferidos por las procuradurías regionales en los departamentos tanto de Tolima como de Cundinamarca. Si la nulidad en sí misma produce la ineficacia de los actos procesales, es realmente necesario revelar sobre qué clase de sanciones o actos procede el control de legalidad. Debido a esa necesidad, se realizó el estudio que se presenta a continuación.

\section{Método investigativo}

La investigación que se llevó a cabo, implico prioritariamente una metodología de investigación cualitativa atendiendo al análisis descriptivo efectuado al contenido de los documentos judiciales relacionados con los actos administrativos disciplinarios y 
los procesos de control judicial a los mismos expedidos en Tolima y Cundinamarca desde el año 2000 hasta el 2011.

\section{Muestra}

En la etapa inicial de este estudio, se buscaron procesos disciplinarios dirigidos contra la Procuraduría General de la Nación. Posteriormente, se seleccionaron únicamente aquellos procesos fallados que contemplasen la acción de nulidad y restablecimiento del derecho como mecanismo de control de judicial a los actos administrativos disciplinarios. Ese criterio de selección se aplicó con el propósito de identificar las causales de nulidad que producen la declaratoria de invalidez de actos administrativos sancionadores en los departamentos del Tolima y de Cundinamarca.

En el Tolima, se hallaron 17 procesos de nulidad y restablecimiento del derecho, asociados con las sanciones disciplinarias de destitución, suspensión, multa y amonestación, interpuestos contra de la Procuraduría General de la Nación. Once de esos procesos eran disciplinarios contra dicha entidad. Esos once procesos fueron la primera muestra de este estudio. La información relacionada con los procesos administrativos en el departamento del Tolima fue obtenida de la Relatoría del Tribunal Administrativo del Tolima.

Por otra parte, a la fecha 28 de septiembre de 2011, se pudo apreciar que existían 1275 procesos disciplinarios dirigidos contra la Procuraduría General de la Nación en el departamento de Cundinamarca. De ese total, tan sólo 62 eran procesos fallados que contemplaban la acción de nulidad y restablecimiento del derecho como mecanismo de control de judicial a los actos administrativos disciplinarios. Sin embargo, sólo se pudo tener acceso oportuno a 21, los cuales fueron suministrados por la Oficina de Archivo de los Juzgados Administrativos de Bogotá y del Tribunal Administrativo de Cundinamarca y por la base sistemática de la Relatoría del Consejo de Estado.

Entonces, la muestra de este estudio estuvo integrada por 11 procesos en Tolima y 21 procesos en Cundinamarca. 


\section{RESUltados DE LA INVESTIGACIÓN}

\section{Causales de nulidad}

Durante la investigación, se identificaron las causales de nulidad que producen la declaratoria de invalidez de actos administrativos sancionadores en los departamentos del Tolima y de Cundinamarca. En el departamento del Tolima, se observó que varios de los accionantes que solicitaron la declaratoria de invalidez del acto administrativo, mediante el cual se les sancionó disciplinariamente, alegaron las tres causales de nulidad dentro de una misma demanda. Sin embargo, la causal de nulidad que más propusieron fue la relacionada con la Violación al Derecho de Defensa del investigado (e.g. Tribunal Administrativo del Tolima, 2003b; 2008a; 2008b), seguida de la Expedición Irregular del Acto Disciplinario con Violación al Debido Proceso (e.g. Tribunal Administrativo del Tolima, 2005a; 2008b) y por último, de la Incompetencia del Funcionario para Proferir el Fallo (e.g. Tribunal Administrativo del Tolima, 2003a).

Específicamente, se halló que la mitad de los servidores públicos sancionados disciplinariamente en el departamento del Tolima invocaban la causal de violación al derecho de defensa y/o audiencia dentro del proceso como razón para tratar de anular el acto administrativo por el cual fueron sancionados. En los fallos disciplinarios estudiados, se vislumbró que las condiciones que motivaron, o circunstancias, a demandar el acto sancionador fueron las siguientes:

1. Perentoriedad, prescripción o vencimiento de términos para continuar adelantando la acción disciplinaria por parte del investigador.

2. Ambigüedad en los cargos formulados al actor dentro de la fase de investigación disciplinaria.

3. Malas adecuaciones de las conductas: gravedad o levedad de la falta.

4. Atipicidad de la conducta. 
5. No controversia oportuna de pruebas o variación constante de cargos dentro del proceso.

6. Inobservancia en decreto o práctica de pruebas, violación de normas constitucionales de rango fundamental, no aplicación de principios dentro del proceso, como lo es el principio de favorabilidad o duda procesal.

7. Incompetencia del funcionario disciplinario para proferir el fallo o para conocer del proceso como consecuencia de vencimiento de términos para agotar vía gubernativa.

De las siete circunstancias expuestas anteriormente, 1, 2, 3, 4 y 5 corresponden a acciones que se enmarcan en la causal de nulidad concerniente a la violación al derecho de defensa del investigado o acusado disciplinariamente. Las circunstancias 5 y 6 son una clara transgresión del debido proceso al sancionado disciplinariamente como irregularidad en la expedición del fallo. La única circunstancia que está relacionada con una directa incompetencia del funcionario para fallar es 7 .

Por otro lado, en el departamento de Cundinamarca, varios de los accionantes que solicitaron la declaratoria de invalidez del acto administrativo mediante el cual se les sancionó disciplinariamente invocaron dentro de una misma demanda las tres causales de nulidad. No obstante, se observó que la causal de nulidad que más sobresalió al interior de las tres fue la relacionada con la expedición irregular del acto disciplinario con violación al debido proceso, seguida de la violación dentro del proceso del derecho a la defensa del sancionado disciplinariamente y, por último, la incompetencia del funcionario para proferir el fallo.

En la investigación, se estableció que el 57,14\% de los servidores públicos sancionados disciplinariamente en el departamento de Cundinamarca alegaron la causal de expedición irregular del acto sancionador con afectación su debido proceso como motivo para tratar de anularlo. Ello se explica luego de haber analizado la información contenida en los fallos disciplinarios estudiados, puesto que al interior de aquellos se hallaron las siguientes circunstancias para demandar el acto sancionador: 
1. Falta de competencia para conocer la Procuraduría General de la Nación en última instancia del recurso de apelación interpuesto por el demandante para revocar la sanción disciplinaria por operar la prescripción de la acción disciplinaria.

2. Indebida notificación de la providencia.

3. Procedencia de prescripción de la acción disciplinaria.

4. Expedición de los actos administrativos con violación a los derechos fundamentales.

5. Emisión del fallo sin existencia de prueba alguna que condujera a la certeza de la existencia de la falta, ni de la consiguiente responsabilidad del disciplinado

6. Desconocimiento del principio que ordena apreciar integralmente las pruebas, aunado a la apreciación de pruebas ineficaces, ilícitas y dubitativas.

7. Inobservancia del principio de legalidad en que deben fundarse los fallos.

De las siete circunstancias previstas en el párrafo anterior, 2, 3, 4, 5, 6 y 7 corresponden a acciones asociadas con la causal de nulidad concerniente a la expedición irregular del fallo disciplinario con afectación del debido proceso del investigado o acusado. Las circunstancias 2 y 3 corresponden a una clara transgresión del derecho de defensa del sancionado disciplinariamente. La única circunstancia relacionada directamente con la incompetencia del funcionario para fallar es la 1.

Con relación a la causal de violación al derecho de defensa del investigado, en algunos de los procesos disciplinarios estudiados en el departamento de Cundinamarca, se determinó la existencia de vicio en la prescripción para que la entidad disciplinaria iniciara la acción investigativa contra el servidor público que presuntamente había cometido una falta disciplinaria. El fenómeno de la prescripción de la acción disciplinaria opera como causal de nulidad de actos administrativos disciplinarios por violación tanto al derecho de defensa como al debido proceso del investigado. 
Esta misma consecuencia se predica en la ocurrencia del fenómeno de la indebida o inoportuna notificación, el cual también genera la nulidad de los actos.

Respecto a la violación al debido proceso en la expedición de un acto disciplinario, por ausencia de aplicación del principio de favorabilidad en la graduación de la falta disciplinaria formulada en el pliego de cargos, deben hacerse dos salvedades. Primero, la vulneración del debido proceso no procede por falta de aplicación de la ley más favorable a un caso en concreto si lo que se pretende realmente en la demanda es obtener una calificación de falta disciplinaria como leve, mas no grave. Esa aspiración desborda la competencia del juez de control de legalidad. En segundo lugar, las divergencias interpretativas respecto del material probatorio no constituyen fuente de violación al debido proceso, dado que este procedimiento sólo permite establecer si el contenido de lo que se prueba puede ser admitido como elemento de convicción y sustento de la consecuencia jurídica, mas no implica admitir el contenido de la prueba en sí misma.

En el estudio realizado a los fallos judiciales que ejercen control de legalidad a los actos disciplinarios proferidos por la Procuraduría General de la Nación en el departamento de Cundinamarca, se pudieron hallar incursas las tres causales de nulidad dentro de un mismo proceso disciplinario. Se puede apelar a las tres causales cuando estas son argüidas o aducidas por el sancionado en la demanda que de nulidad y restablecimiento del derecho se interponga contra el acto sancionador para declarar su invalidez. De la misma manera, se encontró que sólo dos de las tres causales de nulidad resultaron inmersas dentro de un mismo caso, como sería la situación en la que se demanden los actos sancionadores por adolecer los mismos de vicios que atenten tanto al derecho de defensa del acusado como al derecho al debido proceso de aquel.

\section{Pretensiones para invalidar la decisión de origen disciplinario}

Dentro de la investigación adelantada en derecho disciplinario, se tuvieron en cuenta las sanciones descritas al inicio de la revisión bibliográfica y se columbró que estaban 
relacionadas con una pretensión general y con pretensiones particulares dependiendo del tipo de sanción que se le había impuesto al servidor público.

Para revocar la sanción de destitución, se acude a la petición de declaratoria de la nulidad de los actos administrativos a través de los cuales se sancionó disciplinariamente al servidor público. Un ejemplo de ello es el proceso de nulidad y restablecimiento del derecho, dirigido por José Vicente Acosta contra la Procuraduría General de la Nación, para que le revocara la sanción de destitución e inhabilidad general impuesta por parte de la entidad disciplinaria (Tribunal Administrativo del Tolima, 2003b). Si un caso como ese resulta favorable para el amonestado, se espera que se le reintegre al cargo que venía desempeñando antes de imponérsele la sanción disciplinaria. Igualmente, el sancionado ambiciona a que se le efectúe el pago de salarios, prestaciones sociales y demás emolumentos que éste ha dejado recibir durante su ausencia en el ejercicio del cargo. Otro ejemplo de un proceso de nulidad y restablecimiento del derecho con el fin de revocar sanción de destitución e inhabilidad general es el dirigido por Diego Luis Noguera Rodríguez contra la Procuraduría General de la Nación (Consejo de Estado, 2005).

En el caso de la sanción por suspensión, el reprendido hace una petición dirigida a anular la sanción. Así, el servidor público apunta a que se declare la nulidad de los actos administrativos que le causaron sanción disciplinaria. De ser aprobada su petición, se revoca la suspensión para el desempeño del cargo. Posteriormente, se procede al pago de salarios, prestaciones sociales y demás acreencias laborales dejadas de percibir por parte de aquel durante su suspensión en el ejercicio del cargo. Este tipo de pretensión y sus consecuencias pueden ilustrarse con la demanda de nulidad y restablecimiento del derecho interpuesta por Juan Carlos Lozada Saavedra contra la Procuraduría Regional del Tolima y el fallo del Tribunal Administrativo del Tolima (2001).

Asimismo, la situación de la imposición de la multa al disciplinado puede implicar que este último pretenda que se dicte la nulidad del acto que se le reprochó, es decir, la declaratoria de invalidez o anulación del acto que lo sancionó con la multa. Igualmente, el sancionado puede aspirar a que se le exima del pago de la misma. Concretamente, puede citarse el Fallo de demanda de nulidad y restablecimiento del derecho, interpuesta por Neiro Guevara Quezada Saavedra contra la Procuraduría 
General de la Nación para que se le revocara sanción de multa impuesta por parte de la entidad disciplinaria (Tribunal Administrativo del Tolima, 2003b). Esta misma pretensión puede hallarse en la Sentencia 5678 de 2004 del Consejo de Estado y en la Sentencia de 20 de abril de 2006 del Tribunal Administrativo del Tolima.

Finalmente, en materia de la amonestación, el sancionado disciplinariamente dirige sus pretensiones a obtener la declaratoria de nulidad del escrito de amonestación en la demanda que desea interponer contra dicho acto. En consecuencia, espera que se deshagan las anotaciones que se habían relacionado o registrado en su hoja de vida como producto de la imposición de dicha sanción disciplinaria. Además, se pretende que se condene a la entidad disciplinada al pago de perjuicios ocasionados con la imposición de la amonestación. El fallo del Tribunal Administrativo de Cundinamarca (2009) ejemplifica esta pretensión.

En síntesis, en el departamento del Tolima y de Cundinamarca, la pretensión general aducida por los sancionados disciplinariamente es la declaratoria de la nulidad del acto o actos administrativos por el(os) cual(es) se sancionó disciplinariamente al servidor público. Esta pretensión se realiza mediante demandas de nulidad y restablecimiento del derecho dirigidas a anular el acto sancionador. En la Tabla 1 se pueden hallar las pretensiones específicas, discriminadas según el tipo de sanción disciplinar.

Tabla 1. Pretensiones específicas en respuesta a sanciones disciplinares

\begin{tabular}{|c|c|c|}
\hline Sanción & $\begin{array}{l}\text { Pretensiones específicas del } \\
\text { sancionado }\end{array}$ & Consecuencias de la acción \\
\hline Destitución & $\begin{array}{l}\text { Reintegro al sancionado al cargo } \\
\text { que venía desempeñando antes de } \\
\text { imponérsele la sanción disciplinaria }\end{array}$ & $\begin{array}{l}\text { El pago de salarios, prestaciones } \\
\text { sociales y demás emolumentos } \\
\text { dejados de percibir por parte de } \\
\text { disciplinado durante su ausencia en } \\
\text { el ejercicio del cargo. }\end{array}$ \\
\hline Suspensión & $\begin{array}{l}\text { Revocatoria de la suspensión para el } \\
\text { desempeńo del cargo }\end{array}$ & $\begin{array}{l}\text { El pago de salarios, prestaciones } \\
\text { sociales y demás acreencias laborales } \\
\text { dejadas de percibir por parte de } \\
\text { sancionado durante su suspensión en } \\
\text { el ejercicio del cargo. }\end{array}$ \\
\hline
\end{tabular}




\begin{tabular}{|c|c|c|}
\hline Sanción & $\begin{array}{c}\text { Pretensiones específicas del } \\
\text { sancionado }\end{array}$ & Consecuencias de la acción \\
\hline Multa & $\begin{array}{l}\text { Declaratoria de nulidad del acto que } \\
\text { impuso la sanción disciplinaria }\end{array}$ & $\begin{array}{l}\text { La exoneración del cobro y/o pago de } \\
\text { la misma }\end{array}$ \\
\hline Amonestación & $\begin{array}{l}\text { Declaratoria de anulación del escrito } \\
\text { de amonestación }\end{array}$ & $\begin{array}{l}\text { La supresión de las anotaciones que } \\
\text { se habían relacionado o registrado en } \\
\text { la hoja de vida del sancionado como } \\
\text { consecuencia de la imposición de } \\
\text { dicha sanción disciplinaria }\end{array}$ \\
\hline
\end{tabular}

Tabla elaborada por el autor

\section{Concesión o negación de pretensiones disciplinarias}

El acceso o negación de las pretensiones contenidas en la demanda de nulidad y restablecimiento del derecho dirigida a declarar la invalidez de un acto administrativo disciplinario, y por ende, la expedición del fallo judicial a favor o en contra del servidor público, es de carácter relativo en los departamentos de Tolima y Cundinamarca. Para la emisión del mismo, el juzgador tiene en cuenta aspectos sustanciales de carácter punitivo o procesal, tales como la graduación de la sanción impuesta al servidor público, la gravedad o levedad de la falta cometida por el mismo, el acervo probatorio que da cuenta de la certeza de la comisión o no consumación de la conducta por parte del servidor público. Igualmente, el juzgador considera la veracidad del contenido de los aspectos fácticos, pretensiones, normas violadas y concepto de la violación que transcribe en el libelo de demanda el accionante.

En Tolima y en Cundinamarca, el juzgador de segunda instancia accedió a las pretensiones del demandante (a) cuando el investigado disciplinariamente no había cometido la conducta disciplinaria que se le imputaba en el pliego de cargos durante la etapa de investigación disciplinaria, (b) cuando, a pesar de haber consumado la conducta, se le quebrantaron sus derechos a ser tanto investigado como a ser juzgado por un funcionario competente del orden disciplinario, (c) cuando le fueron vulnerados su derecho de defensa o al debido proceso, en razón a que las etapas procesales no fueron surtidas de forma oportuna, y por lo tanto, dieron lugar a la 
perentoriedad de los términos procesales o (d) cuando los hechos imputados en el pliego de cargos carecían de fundamentos fácticos-jurídicos o eran ambiguos o vagos.

En contraste con lo expuesto en el párrafo anterior, se pudo observar en ambos departamentos que las pretensiones de las demandas de nulidad y restablecimiento del derecho interpuestas por los sancionados disciplinariamente, no prosperaron en razón a que (a) no hubo acervo probatorio suficiente o creíble para demostrar la procedencia tanto los hechos como las pretensiones de la acción o (b) quedó debidamente comprobada la consumación de la conducta por parte del servidor público, sin que hubiese existido causal alguna de invalidez procesal que por concepto de falta de competencia, violación al derecho de defensa o violación al debido proceso que diera mérito a la declaratoria de nulidad de todo lo actuado dentro del proceso.

En el departamento del Tolima, se negaron ocho de las once pretensiones disciplinarias. Por ejemplo, el Tribunal Administrativo del Tolima (2005b) revocó la sanción de inhabilidad por 12 meses en el ejercicio del cargo impuesta por la Procuraduría Regional del Tolima Gilberto Barragán Ávila después de que éste último impusiera una demanda de nulidad y restablecimiento del derecho. Otro ejemplo de negación de pretensiones disciplinarias es la Sentencia 528 de 2003 del Tribunal Administrativo del Tolima.

Luego de analizar estadísticamente las sentencias proferidas por la Jurisdicción de lo Contencioso Administrativo en el Departamento de Cundinamarca, se estableció que las pretensiones se negaron en un $80,95 \%$ de los casos. Ese tipo de fallo se debe primordialmente a la comprobación de la comisión de la falta disciplinaria por parte del disciplinado, sin transgresión al factor de competencia, al derecho de defensa y/o audiencia del investigado, o al debido proceso.

No obstante lo anterior, vale la pena resaltar que en las múltiples sentencias emanadas del Consejo de Estado que ejercen control de revisión a los fallos proferidos por el Tribunal Administrativo de Cundinamarca, tendientes a realizar control de legalidad a los actos administrativos disciplinarios proferidos por la Procuraduría General de la Nación en este departamento, se revocaron fallos en contra del sancionado disciplinariamente. 


\section{Fallos de carácter inhibitorio}

En el estudio realizado a las providencias que se dirigen en contra de la Procuraduría General de la Nación en el departamento del Tolima, se halló que existe la posibilidad por parte de la Jurisdicción de lo Contencioso Administrativo de declararse inhibida para fallar las pretensiones a favor o en contra del sancionado disciplinariamente. Sin embargo, en el análisis estadístico descriptivo de las pretensiones que son concedidas o negadas por iniciación de acciones de nulidad y restablecimiento del derecho contra los actos administrativos disciplinarios emanados de dicha entidad, realizado durante esta investigación, se halló que los casos en que el órgano judicial de segunda instancia o de revisión se abstuvo de negar o conceder las pretensiones contenidas en la demanda fueron poco frecuentes. Según indican los fallos del Tribunal Administrativo del Tolima, la abstención se debió a la ineptitud de demanda, en razón a la falta o ausencia de algún requisito sustancial dentro del proceso, por ejemplo, Tribunal Administrativo del Tolima (2003b).

\section{Conclusiones}

La gran mayoría de los casos de control de legalidad judicial que adelanta la Jurisdicción de lo Contencioso Administrativo sobre los fallos disciplinarios proferidos por la Procuraduría General de la Nación y por las procuradurías provinciales y regionales del país se lleva a cabo por la entidad disciplinaria sobre la cual recae la última instancia. Entonces, es en la Procuraduría General de la Nación, asentada en los respectivos departamentos y/o municipios, donde se origina la controversia de orden disciplinario. La Procuraduría General de la Nación es el órgano que detenta la competencia para conocer los fallos disciplinarios que provienen en apelación por parte de sus seccionales.

La causal de nulidad menos invocada por los sancionados disciplinariamente tanto en Tolima como Cundinamarca es la atinente a la falta de competencia del funcionario disciplinario para proferir el fallo disciplinario. La causal de nulidad más invocada por los sancionados disciplinariamente en el Tolima es la relacionada con la violación al derecho de defensa del investigado. La causal de nulidad más invocada por los 
sancionados disciplinariamente en Cundinamarca es la concerniente a la violación al debido proceso. Igualmente, de conformidad con el análisis efectuado se puede corroborar que, atendiendo al problema de investigación planteado, la causal de invalidez de los actos jurídicos en reflexión que más predomina es la referente a la expedición irregular del acto administrativo sancionador con violación al debido proceso.

Tanto en Tolima como en Cundinamarca, siempre se formula la misma pretensión general: invalidar la nulidad de actos administrativos de tipo sancionatorio. Lo que varía es la petición específica, la cual depende de la sanción impuesta al servidor público que recibe la sanción (destitución, suspensión, multa o amonestación). Por ejemplo, en el caso de destitución, el funcionario exige el reintegro al cargo que ocupaba o se solicita la eliminación del llamado de atención en la hoja de vida del sancionado con una amonestación.

En ambos departamentos, se observa, conforme al análisis estadístico descriptivo de los procesos judiciales fallados a favor o en contra de los disciplinados, que las pretensiones de invalidar los actos sancionadores proferidos por la Procuraduría General de la Nación son negadas frecuentemente. La razón principal para ese fallo es la comprobada comisión de la falta disciplinaria por parte del servidor público, desprovista o exenta de vicios por falta de competencia, violación al derecho de defensa y/o audiencia del acusado o expedición irregular del acto administrativo sancionador con vulneración del derecho al debido proceso.

Finalmente, es significativo anotar que hay una diferencia significativa entre el control judicial que se adelanta a los fallos disciplinarios proferidos por la Procuraduría General de la Nación en el departamento del Tolima y los de Cundinamarca. De acuerdo con el análisis de las sentencias de nulidad y restablecimiento del derecho proferidas por la Jurisdicción Contenciosa Administrativa en el departamento de Cundinamarca, los fallos de carácter inhibitorio no son frecuentes. Esto indica que las personas que demandan las providencias disciplinarias en esta zona geográfica interponen las demandas de nulidad y restablecimiento del derecho de forma adecuada. En dichas demandas, se surten las formalidades sustanciales que requiere el caso. De este modo, se eluden defectos como la inepta demanda. 


\section{REFERENCIAS}

Bulla, J. (2009) Código Disciplinario Único. Ley 734 de 2002 (Segunda parte). Bogotá: Editorial Temis.

Consejo de Estado (1990). Sentencia de 15 de noviembre de 1990. Expediente No. 2339. Consejero ponente: Álvaro Lecompte Luna. Consultada en https://www.redjurista.com/ Documents/ce-sec2-exp1990-n2339.aspx

Consejo de Estado, Sección Primera. (1995). Sentencia de 26 de octubre de 1995. Magistrado ponente: Libardo Rodríguez.

Consejo de Estado (2002). Sentencia 07968 de 2002. 19 de marzo de 2009. Magistrada ponente: Bertha Lucía Ramírez de Páez.

Consejo de Estado (2004). Sentencia 5678 de 2004. 07 de Octubre de 2010. Expediente No. 2137-09. Magistrado ponente: Víctor Hernando Alvarado Ardila. Radicación: 25000-23-25-000-2004-05678-02.

Consejo de Estado (2004). Sentencia 2982 de 2004. Magistrado ponente: Víctor Hernando Alvarado Ardila. Consultada en la Relatoría web del Consejo de Estado.

Consejo de Estado (2005). Sentencia 113 de 2005. Magistrado ponente: Víctor Hernando Alvarado Ardila. Consultada en la Relatoría web del Consejo de Estado.

Consejo de Estado (2007). Sentencia 00066 de 2007. Magistrado ponente: Alfonso Vargas Rincón. Consultada en la Relatoría web del Consejo de Estado.

Consejo de Estado (2011a). Sentencia de 07 de Abril de 2011. Radicación: 2008-00072. Magistrado ponente: Víctor Hernando Alvarado Ardila. Sección Segunda-Subsección B. Consultada en la Relatoría web del Consejo de Estado. 
Consejo de Estado (2011b). Sentencia de 28 de mayo de 2011. Magistrado ponente: Víctor Hernando Alvarado Ardila. Sección Segunda. Radicación: 2010-00020. Consultada en la Relatoría web del Consejo de Estado.

Corte Constitucional (1994). Sentencia T-393/94, 07 de Septiembre de 1994. Magistrado ponente: Antonio Barrera Carbonell.

Corte Constitucional (1996). Sentencia C-280 de 25 de junio de 1996. Magistrado ponente: Alejandro Martínez Caballero.

Corte Constitucional (2002). Sentencia C-181 de 12 de marzo de 2002. Magistrado ponente: Marco Gerardo Monroy Cabra.

Gómez, C. (2009). Elementos y Propuestas para el Control Contencioso Administrativo de la Actividad Disciplinaria (Primera edición, Volumen 3). Bogotá: Ediciones Nueva Jurídica.

Gordillo, A. (2012). Libro II del Tratado de derecho administrativo y obras selectas (Capítulo 3: Teoría de las nulidades del acto administrativo). Buenos Aires: FDA. Extraído de http:// www.gordillo.com/tomo5.html

Isaza, C. (2009). Teoría General del Derecho Disciplinario, Antecedentes Históricos, Sustanciales y Procesales (Segunda edición). Bogotá: Editorial Temis.

Ley 734 del 05 de febrero de 2002. Código Disciplinario Único. Consultada en http://www. procuraduria.gov.co/guiamp/media/file/Macroproceso\%20Disciplinario/L-734-02.htm

Ley 1437 del 18 de enero de 2011. Código de Procedimiento Administrativo y de lo Contencioso Administrativo. Consultada en http://www.alcaldiabogota.gov.co/sisjur/normas/ Norma1.jsp?i=41249

Maurino, A. (1995). Nulidades Procesales. Buenos Aires: Editorial Astrea.

Navas, J. (2004). Código Disciplinario Único. Ley 734 de 2002. Concordado, Comentado, Jurisprudencia y Práctica (Segunda edición). Bogotá: Librería Ediciones del Profesional Ltda. 
Orjuela, M. P. (2003). Proceso Disciplinario en la Práctica (Primera edición). Bogotá: Librería Ediciones del Profesional Ltda.

Palacio, J. Á. (2010). Derecho Procesal Administrativo (Séptima edición). Medellín: Editorial Librería Jurídica Sánchez Ltda.

Procuraduría General de la Nación (2004). Código Disciplinario Único. Ley 734 de 2002. Bogotá: Editorial Instituto de Estudios del Ministerio Público.

Reyes, J. F. (2003). Dos Estudios de Derecho Sancionador Estatal. Colección Derecho Disciplinario $N^{\circ} 3$. Bogotá: Editorial Institutos de Estudios del Ministerio Público.

Rodríguez, L. (2008). Derecho administrativo general y colombiano (Decimosexta edición). Bogotá: Editorial Temis.

Tribunal Administrativo de Cundinamarca (2008). Sentencia de 18 de diciembre de 2008. Radicación: 2003-09519. Magistrado ponente: César Palomino Cortés. Sección SegundaSubsección B. Obtenida de la Relatoría del Tribunal Administrativo de Cundinamarca.

Tribunal Administrativo de Cundinamarca (2009). Sentencia de Mayo 28 de 2009. Radicación: 2007-0294. Magistrado ponente: José Antonio Arciniegas. Obtenida de la Relatoría del Tribunal Administrativo de Cundinamarca.

Tribunal Administrativo de Cundinamarca (2010). Sentencia de 20 de mayo de 2010. Radicación: 2006-00197. Magistrado ponente: César Palomino Cortés. Obtenida de la Relatoría del Tribunal Administrativo de Cundinamarca.

Tribunal Administrativo del Tolima (2001). Sentencia 0007 de 2001. Magistrada ponente: Susana Nelly Acosta Prada. Obtenida de la Relatoría del Tribunal Administrativo del Tolima.

Tribunal Administrativo del Tolima (2003a). Sentencia 0528 de 2003. Magistrado ponente: José Aleth Ruiz Castro. Obtenida de la Relatoría del Tribunal Administrativo del Tolima. 
Tribunal Administrativo del Tolima (2003b). Sentencia 1444 de 2003. Magistrado ponente: Carlos Arturo Mendieta Rodríguez. Obtenida de la Relatoría del Tribunal Administrativo del Tolima.

Tribunal Administrativo del Tolima (2005a). Sentencia 1047 de 2005. Magistrado ponente: José Aleth Ruiz Castro Muñoz. Obtenida de la Relatoría del Tribunal Administrativo del Tolima.

Tribunal Administrativo del Tolima (2005b). Sentencia 2961 de 2005. Magistrada ponente: Susana Nelly Acosta Prada. Obtenida de la Relatoría del Tribunal Administrativo del Tolima.

Tribunal Administrativo del Tolima (2006). Sentencia de 20 de abril de 2006. Radicación: 2004-00848. Magistrada ponente: Amparo Oviedo Pinto. Sección Segunda-Subsección C. Obtenida de la Relatoría del Tribunal Administrativo de Cundinamarca.

Tribunal Administrativo del Tolima (2008a). Sentencia 005 de 2008. Magistrado ponente: Carlos Arturo Mendieta Rodríguez. Obtenida de la Relatoría del Tribunal Administrativo del Tolima.

Tribunal Administrativo del Tolima (2008b). Sentencia 285 de 2008. Magistrado ponente: Jorge Alfonso Gutiérrez Muñoz. Obtenida de la Relatoría del Tribunal Administrativo del Tolima.

Villegas, Ó. (2003). El proceso disciplinario. Ley 734 de 2002. Bogotá: Ediciones Jurídicas Gustavo Ibáñez Ltda.

Younes, D. (2007). Curso de derecho administrativo (Octava edición). Bogotá: Editorial Temis. 